\title{
Method for comparing current versus recommended housing conditions in dairy cattle production
}

\author{
Marek Gaworski ${ }^{1}$ and Michał Boćkowski² \\ ${ }^{1}$ Department of Production Management and Engineering, Warsaw University of Life Sciences, \\ Nowoursynowska str. 164, 02-787 Warsaw, Poland \\ ${ }^{2}$ Rolstal Company, Różańska str. 45, 07-300 Ostrów Mazowiecka, Poland \\ e-mail: marek_gaworski@sggw.pl
}

\begin{abstract}
The objective of the study was to propose a method to assess how well some housing conditions in barns meet national standards and recommendations. The key element of the method was to investigate the index of technical standards fulfilment (ITSF), which shows differences between current housing conditions created by barn facilities and some standards. The lower differences are expressed by higher ITSF value, whereas the index values range from 0 to 1. Data collected in 38 dairy farms (with tie-stall and freestall housing systems) were used for the ITSF index analyses. The ITSF index values for the two compared housing systems were calculated for measurements carried out in four zones in each barn: lying, social, feeding and milking areas. There were higher average ITSF index values for the freestall system than for the tie-stall housing system across all investigated zones included in the barns. Investigations can support farmers to improve some conditions of dairy production in the barns including consciousness of some standards on dairy facilities and cow comfort.
\end{abstract}

Key words: barn, cow rearing system, engineering design, index, method, standards fulfilment

\section{Introduction}

On dairy farms the effects of technical, technological and biological progress as well as their mutual relationships can be investigated. Research considerations are developed in many areas of the dairy production system, where animal welfare is currently one of the most significant fields of inquiry.

A growing topic in science (von Keyserlingk et al. 2009) is to help identify and better understand animal welfare as a key element of the dairy production system and as a pillar of sustainability. The concept of farm animal welfare is rooted in public concern for how animals are treated and today integrates the interests and concerns of different stakeholders, including producers, governments, the general public and, of course, the animals themselves.

Discussions of welfare have provided inspiration to develop the idea of how to measure animal welfare and its relationship to surrounding environments. It is possible to identify many approaches to measure farm animal welfare, including the welfare of dairy cattle. These are consumer, animal and production-based measures, which are all important from the viewpoint of food product quality chains (Blokhuis et al. 2003). Each approach can be characterized by specific features. One such feature is including both the surroundings and environment in many definitions concerning animal welfare. The surroundings and environment constitute a part of animal production conditions, so production-based measures are valuable for animal welfare research analyses. The productionbased approach appears to be the most practical approach to measuring some conditions for predicting farm animal welfare, and its results can be translated into current practices in livestock farming.

Many methods are presented in the specialist literature, such as assessing welfare in loose housed dairy cows at the farm level (Capdeville and Veissier 2001), decision support systems to assess farm animal welfare (Bracke et al. 2001), and three scoring methods for assessment of housing conditions of dairy cows in littered loose housing systems (Hörning 2001). These scoring methods include TGI 35 (Bartussek 1999), TGI 200 (Sundrum et al. 1994) and ALD, or the Assessment scheme for Littered loose housing systems of Dairy cows (Hörning 1997). Moreover, it is possible to find other examples, such as the Welfare Quality scoring system and propositions presented in the Welfare Quality Network (www.welfarequalitynetwork.net). The development and improvement of animal welfare assessment methods result from critical discussion concerning methods and their details, e.g., within the TGI 35 L and TGI 200 approach some criteria are included (judged) several times in some categories (like access to pasture or outside run). Another critical aspect shows that some criteria with importance for welfare assessment can be missed; as a result, it is possible to observe the reduced sensitivity of some assessment methods. 
The precision of the instructions used for assessments and the repeatability of measurements concerning welfare are also important problems. Moreover, it is essential to keep in mind the objective of the assessment when judging its validity (Alban et al. 2001) in addition to reliability and feasibility issues concerning on-farm welfare assessment (Knierim and Winckler 2009).

The review of some methods of animal welfare assessment suggests that subjective judgement of welfare and conditions is a problem when deciding welfare. It is a problem especially when criteria for livestock (including differences between animals) as well as production conditions (including issue of setting the thresholds) are scored on a scale with a proposed number of points. These more or less subjective judgements can result in different assessment of some details connected with animal production, such as the actual state of facilities in livestock buildings.

The aforementioned state of facilities is composed of many technical and technological details in the barn. The technical details include such data as dimensions for freestalls or cubicles and other equipment in feeding, walking and milking areas in the barn. The significance of technical elements in the technology of farm dairy production has been demonstrated by many experiments, where the effects of the neck-rail position (Fregonesi et al. 2009), both the placement (Tucker et al. 2005) and size of lying stalls (Tucker et al. 2004), brisket-board parameters (Tucker et al. 2006), level of bedding material (Drissler et al. 2005) and other factors are discussed with regard to their impacts on cow behaviour, preferences, stall cleanliness and general animal comfort and welfare. Points of reference for the discussed results are numerous recommendations resulting from animal body sizes (McFarland and Gamroth 1994, Bickert 2000), which are given in binding standards at the national scale. The main premise here is the idea that well-designed stalls provide advantages for dairy cows in both tie-stall and freestall housing (Ceballos et al. 2004) in addition to advantages for dairy cows that are associated with well-designed floors (Haley et al. 2001), feeding systems (de Vries et al. 2004), water intake systems (McFarland 2000) and more.

Many investigations have shown that cattle reduced comfort and welfare levels are connected to the relationships between animals and equipment used in barns. As such, the technical elements in barns constitute important components of animal welfare improvement. The research problem can be focused on assessment of the production environment created by technical elements including places (areas) where contacts between animals and the equipment can be identified. Such an approach inspires the development of an experimental tool to investigate details concerning equipment in dairy farm production. The objective of the study was to develop a method to assess how well some housing conditions in barns meet national standards and recommendations.

This research objective can be complemented by its practical effect resulting from the measured data, i.e., proposing a simple approach that can help farmers and researchers assess conditions in the livestock building associated with animal welfare. The general idea of the method is based on measuring the technical parameters in space for animals in livestock buildings and interpreting these measurements in the context of national standards, requirements and recommendations concerning animal housing conditions.

\section{Materials and methods}

The method to assess conditions associated with animal welfare was applied to measured data within a group of dairy farms.

\section{Dairy farm selection and their general description}

The study was conducted in the Mazovia and Podlasie regions of Poland. These regions in central and eastern Poland are characterized by their high potential for dairy production against the background of the country. A group of 38 family dairy farms was preselected for measurements including criteria such as cattle housing system, herd size, structure of dairy cattle herd and technical facilities. The farms were numbered for more clear elaboration of collected data. Each farm managed one barn for dairy cows. Nineteen farms used the tie-stall system and nineteen farms used the freestall housing system. The group of farms with tie-stall systems was characterized by the following data: average herd size $29 \pm 14$ milking cows ( \pm SD, ranging from 8 to 60 cows) producing $5.261 \pm 1.329$ $\mathrm{kg}$ (ranging from 3,333 to 8,400 kg) annually (based on the annual milk yield estimated by the national milk recording system for some farms and for the others by dairy plants purchasing milk from farms including the farm's own consumption). The average herd size in the freestall housing farms was $86 \pm 38$ milking cows ( \pm SD, ranging from 30 to 150 cows) producing $6.749 \pm 1.483 \mathrm{~kg}$ (ranging from 3,900 to 9,000 kg) annually based on the annual milk yield estimated by the national milk recording system. The majority of the farms $(n=35)$ milked twice daily, but three farms equipped with AMS (automatic milking systems) milked on average 2.8 times per day. 


\section{Collection of data in the farms}

All selected dairy farms were visited once, between summer 2011 and spring 2012. Each visit consisted of activities conducted in the same order, i.e., farm survey (carried out with owner of the farm), indoor measurements, observation (to identify elements of risk in the barn) and taking photographs (to record some details concerning equipment in the barn and cows). To carry out the first three tasks, a questionnaire was prepared.

The information part of the questionnaire included general data concerning the dairy farm, delivered by farmer and milking control reports. The following information was collected: cow herd size, number of other animals (calves, heifers), production indices (such as annual milk yield per cow), amount of milk delivered to dairy plant (per month and year), and number of animal health problems. Moreover, general information on plant production on the farm was collected, i.e., cropland and grassland areas and the yield of the main crops. The number of persons employed in the farm was also recorded. The information part of the questionnaire also described some details concerning the barns on each farm, e.g., the number of doors and windows, number of feeding alleys, system of manure / slurry removing and storage, and type of bedding at the lying area.

The measuring part of the questionnaire included a set of tables to collect technical parameters measured in the following areas in each barn: lying, feeding / drinking, social / walking and milking. The distinguished areas were also interchangeably named "zones" and, for further analyses and discussions, are denoted as lying, feeding, social and milking zones.

When collecting data in the lying area, some rules were followed. In each barn with the tie-stall system, two lying stalls were measured for each row, i.e., one stall located at the end of the row and one stall in the middle of the row. The same rule was used for each barn with the freestall system; i.e., two stalls (one middle and one outermost) were measured per row, taking into account one row by the wall (if present) and another independent row or two rows (in the "head to head" system). Both tie-stall and freestall barns were also evaluated by paying special attention to the amount of bedding material (when used) or thickness of rubber mats.

The following parameters were measured in each stall in the barn with the tie-stall system: width (between front stanchions and at the end of partitions, if present), length of stall (between the front wall at the feeding alley and rear channel with manure scraper or openwork channel for slurry collection), height and length of the partition, and depth of manure channel. In the barns with the freestall system, the following lying stall parameters were measured: width (between partitions in two places: over neck-rail and at the rear part of the stall), length of stall (between brisket board and rear curb), height of the rear curb, and neck-rail position (height over the lying stall surface).

For the feeding area, the following measurements were carried out in each barn with the tie-stall system: width of access (per cow) to the feeding alley, the vertical distance between the feeding alley and the floor at the lying area, the width of the feeding alley and manger (if present), and the height of the wall separating the feeding alley from the lying area. In the barns with freestall systems, additional parameters were measured in the feeding area, including the height of the feeding ladder and the total width of access to the feeding alley (to calculate the width per cow). Moreover, some data concerning drinking systems were collected, including the number of drinking bowls and their location and height over the floor.

In the social / walking area, the following quantities were measured in each barn with a tie-stall system: manure / walking alley(s), steel or concrete grid for faeces collecting and their details, i.e., the beam width and spacing. In the barns with freestall systems, we measured aspects of barn such as the width of the manure alleys near the feeding alley, the width between the rows with lying stalls and parameters of the slotted floor (width of beams and beam spacing). Moreover, some data concerning outdoor yards in farms with freestall systems were collected, including the height and width of the exit gate, the height of the fence, and the area of outdoor yards per animal.

The construction details in milking areas were assessed in barns with milking parlours. The following data were collected: the width of the milking parlour, the length and width of the milking channel, the length and width of the milking stall, the waiting area sizes, including the area per cow, the width of the milking parlour entrance gate, the number of milking stalls and other details. In the barns with tie-stall systems, the milking area is functionally connected to the lying area, so only some details, such as the location (over the ground) of vacuum and milking pipelines, were measured. In the farms with automatic milking systems, only basic parameters (sizes) for the milking stalls and waiting areas were measured. 
The parameters measured in different zones (based on the range of values measured in individual barns) and the recommended parameters (reference values) for tie-stall barns and freestall barns in Poland are presented in Table 1 and Table 2 respectively.

Table 1. Parameters measured in tie-stall barns in different zones (based on the range of values measured in individual barns) vs. recommended parameters (reference values) in Poland

\begin{tabular}{|c|c|c|}
\hline Description & $\begin{array}{l}\text { Recommended } \\
\text { size(s) / amount } \\
\text { / area }\end{array}$ & $\begin{array}{l}\text { Range of values } \\
\text { measured in the } \\
\text { barns }\end{array}$ \\
\hline \multicolumn{3}{|l|}{ Lying / milking area } \\
\hline Lying stall: width & $110-120 \mathrm{~cm}$ & $95-123 \mathrm{~cm}$ \\
\hline length & $160-185 \mathrm{~cm}$ & $161-205 \mathrm{~cm}$ \\
\hline Partition between lying stalls: length & $60-100 \mathrm{~cm}$ & $65-105 \mathrm{~cm}$ \\
\hline height & $90-100 \mathrm{~cm}$ & $65-108 \mathrm{~cm}$ \\
\hline Depth of manure channel & $20 \mathrm{~cm}$ & $13-25 \mathrm{~cm}$ \\
\hline Thickness of rubber mats & $\geq 2.5 \mathrm{~cm}$ & $2.5-5.0 \mathrm{~cm}$ \\
\hline Amount of bedding material (per stall) & $5 \mathrm{~kg}$ & $1.5-5 \mathrm{~kg}$ \\
\hline \multicolumn{3}{|l|}{ Feeding area } \\
\hline Height of the wall separating the feeding alley from the lying area & $30 \mathrm{~cm}$ & $0-21 \mathrm{~cm}$ \\
\hline Vertical distance between the feeding alley and the floor at the lying area & $8-10 \mathrm{~cm}$ & $6-12 \mathrm{~cm}$ \\
\hline Width of the manger & $40-60 \mathrm{~cm}$ & $37-90 \mathrm{~cm}$ \\
\hline Width of access (per cow) to the feeding alley with manger & $70 \mathrm{~cm}$ & $58-122 \mathrm{~cm}$ \\
\hline Height of drinking bowls over the floor & $\leq 70 \mathrm{~cm}$ & $33-62 \mathrm{~cm}$ \\
\hline \multicolumn{3}{|l|}{ Social / walking area } \\
\hline Width of manure / walking alley: alley at wall & $190-210 \mathrm{~cm}$ & $124-270 \mathrm{~cm}$ \\
\hline central alley & $200-250 \mathrm{~cm}$ & $160-250 \mathrm{~cm}$ \\
\hline $\begin{array}{r}\text { Concrete grid for faeces collecting: width of beams } \\
\text { beam spacing }\end{array}$ & $\begin{array}{l}11-14 \mathrm{~cm} \\
3.5-4.0 \mathrm{~cm}\end{array}$ & No present \\
\hline
\end{tabular}

The detailed measurements of technical parameters in each barn zone were carried out using two tools: a measuring tape (measuring range $7.5 \mathrm{~m}$ and measuring accuracy $0.001 \mathrm{~m}$ ) and a laser meter (measuring range $200 \mathrm{~m}$ and measuring accuracy $0.0015 \mathrm{~m}$ ) with an optic system of fixed reference point.

\section{Methodological approach to data analyses}

The recorded parameters were selected to reflect national standards and recommendations on animal production and animal welfare. The recommended parameters - sizes of particular structural elements in each barn zone were included. Based on the measured parameters and the corresponding recommended parameters, an index of technical standards fulfilment (ITSF) was calculated. To define the value of the proposed ITSF for the individually considered parameters in some barns, a specific algorithm was proposed (Fig. 1).

According to the algorithm in Figure 1, it is possible to calculate an ITSF value for one parameter. The proposed method to assess some conditions for animals in the barn is characterized by a maximum value of 1.0 for the final index. Values lower than 1.0 indicate differences between the current state of technical conditions in the barn and a certain optimum state, where all necessary technical needs are fulfilled and, as a result, the ITSF value equals 1.0.

In particular zones, there are different numbers of measured parameters. Thus, the next step involves calculating the ITSF for each zone based on the individual ITSF values for the parameters within that zone.

In most cases, the recommended standards concerning the technical parameters in a particular barn zone are given as ranges of values. Thus, the proposed algorithm can be used. However, some standards are given as a minimum value, e.g., area per animal (cow, heifer), in loose housing systems. In such cases, when the measured value is higher than the recommended value, the ITSF index can be included as 1.0 in further analyses. 
Table 2. Parameters measured in freestall barns in different zones (based on the range of values measured in individual barns) vs. recommended parameters (reference values) in Poland

\begin{tabular}{|c|c|c|}
\hline Description & $\begin{array}{c}\text { Recommended } \\
\text { size(s) / amount / } \\
\text { area }\end{array}$ & $\begin{array}{c}\text { Range of values } \\
\text { measured in the } \\
\text { barns }\end{array}$ \\
\hline \multicolumn{3}{|l|}{ Lying area } \\
\hline Lying stall at wall: width & $115-120 \mathrm{~cm}$ & $102-126 \mathrm{~cm}$ \\
\hline length & $225-245 \mathrm{~cm}$ & $216-261 \mathrm{~cm}$ \\
\hline Lying stalls in two rows (head-to-head): width & $115-120 \mathrm{~cm}$ & $93-118 \mathrm{~cm}$ \\
\hline length & $215-235 \mathrm{~cm}$ & $201-248 \mathrm{~cm}$ \\
\hline Height of neck-rail over the lying stall surface & $110 \mathrm{~cm}$ & $106-118 \mathrm{~cm}$ \\
\hline Height of rear curb & $20 \mathrm{~cm}$ & $12-26 \mathrm{~cm}$ \\
\hline Thickness of rubber mats & $\geq 2.5 \mathrm{~cm}$ & $2.0-5.0 \mathrm{~cm}$ \\
\hline Amount of bedding material (per stall) & $5 \mathrm{~kg}$ & $3-6 \mathrm{~kg}$ \\
\hline \multicolumn{3}{|l|}{ Feeding area } \\
\hline Height of the feeding ladder over the feeding area & $145 \mathrm{~cm}$ & $135-150 \mathrm{~cm}$ \\
\hline Height of the wall separating the feeding alley from the pen & $40-55 \mathrm{~cm}$ & $35-53 \mathrm{~cm}$ \\
\hline Vertical distance between the feeding alley and the floor at the pen & $8-25 \mathrm{~cm}$ & $21-32 \mathrm{~cm}$ \\
\hline Width of manger at feeding alley & $40-60 \mathrm{~cm}$ & $55-80 \mathrm{~cm}$ \\
\hline Width of access (per cow) to the feeding alley & $70 \mathrm{~cm}$ & $50-85 \mathrm{~cm}$ \\
\hline Height of drinking equipment over the floor & $\leq 90 \mathrm{~cm}$ & $55-100 \mathrm{~cm}$ \\
\hline \multicolumn{3}{|l|}{ Social / walking area } \\
\hline Width of the manure (scraper) alley near the feeding alley & $300-360 \mathrm{~cm}$ & $270-340 \mathrm{~cm}$ \\
\hline Width between the rows with lying stalls & $240-280 \mathrm{~cm}$ & $234-310 \mathrm{~cm}$ \\
\hline Width of the exit gate - access to outdoor yard & $120-150 \mathrm{~cm}$ & $120-200 \mathrm{~cm}$ \\
\hline Height of the exit gate - access to outdoor yard & $120-150 \mathrm{~cm}$ & $100-133 \mathrm{~cm}$ \\
\hline Area of outdoor yard per animal & $4-4.5 \mathrm{~m}^{2}$ & $4.5-17.6 \mathrm{~m}^{2}$ \\
\hline Height of the fence around the outdoor yard & $120 \mathrm{~cm}$ & $120-130 \mathrm{~cm}$ \\
\hline Parameters of the slotted floor: width of beams & $11-14 \mathrm{~cm}$ & $10-12 \mathrm{~cm}$ \\
\hline beam spacing & $3.5-4.0 \mathrm{~cm}$ & $0-4.2 \mathrm{~cm}$ \\
\hline \multicolumn{3}{|l|}{ Milking area } \\
\hline Width of the milking parlour entrance gate & $\geq 90 \mathrm{~cm}$ & $80-150 \mathrm{~cm}$ \\
\hline Waiting area - area per cow & $\geq 1.5 \mathrm{~m}^{2}$ & $1.3-2.5 \mathrm{~m}^{2}$ \\
\hline
\end{tabular}

\section{Statistical analysis}

Statistical analysis of the collected and calculated data was carried out with use of Statistica v.12. The descriptive statistical indicators, i.e. mean, standard deviation, minimum and maximum were determined for the assessed index of technical standards fulfilment (ITSF). The comparison of data obtained in the two different housing systems (tie-stall and freestall system) was conducted using the ANOVA test. Taking the housing system as a main criterion for a more detailed comparison, the variance of the ITSF values was analysed for individual zones in the investigated barns. The statistical model for ITSF index included the fixed effects of four zones in barns (lying, social, feeding and milking zone). The correlations of different variables (production parameters and technological data) collected in the 38 investigated dairy farms were described with the Pearson correlation coefficient. The $p$ values less than 0.05 were considered to be significant. 


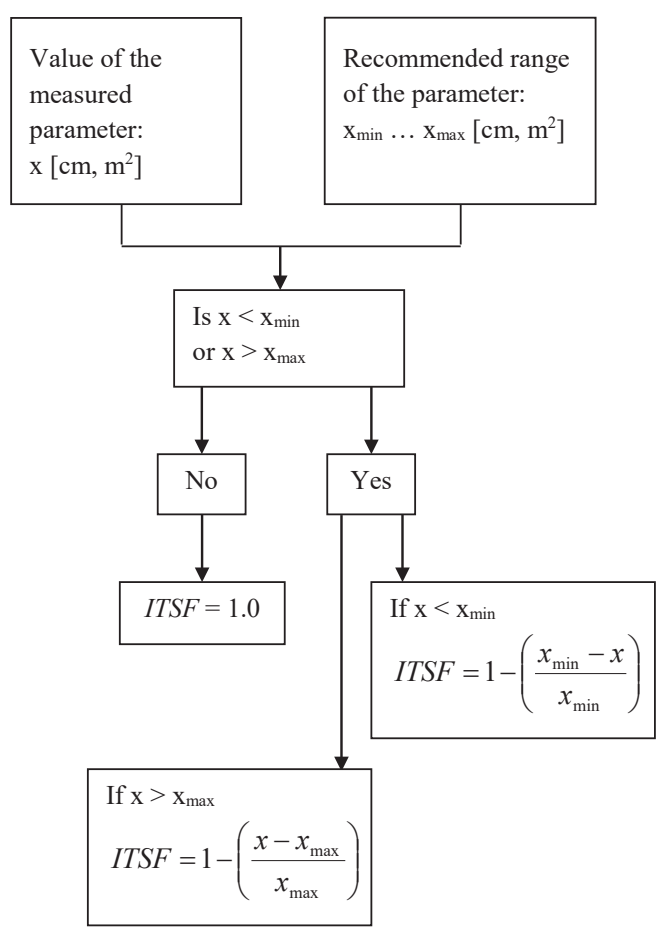

Fig. 1. An algorithm to calculate the value of the index of technical standards fulfilment (ITSF); the meaning of particular symbols is as follows: $x=$ measured parameter, $x_{\min }=$ minimum value of the recommended parameter, $x_{\max }=$ maximum value of the recommended parameter

\section{Results}

The ITSF shows different values for the two housing systems and four zones within each barn when considering data for the 38 investigated dairy farms (Table 3).

It is possible to discern some characteristic tendencies. Generally, there are higher mean ITSF values for freestall systems than for tie-stall housing systems across all zones where cows have contact with the technical infrastructure in the barns. Considering the data within zones can be interesting that the lowest mean ITSF values were found for the feeding zone (FZ) for both housing systems, whereas the highest mean ITSF values were found for social zone in systems. For freestall housing system the difference between the highest and lowest mean ITSF value, including all considered zones, was 0.067 , while for tie-stall system the difference amounted to 0.149 , i.e. over two times more. The minimum ITSF values for all zones in barns with freestall housing systems are generally higher than the minimum ITSF values for the considered zones in barns with tie-stall system. However, the maximum ITSF values for both freestall and tie-stall systems, including all zones, generally have lower variation, especially in barns with freestall housing systems. It can be noted that highest maximum ITSF value of 1.0 was found both in barns with freestall and with tie-stall housing systems. Such cases were found only in the social zone.

Table 3. ITSF mean values \pm SD for the set of investigated barns and their selected traits, i.e., housing system and zone type, including $p$-value

\begin{tabular}{llllll}
\hline Housing system & ITSF value & Lying zone (LZ) & Social zone (SZ) & Feeding zone (FZ) & Milking zone (MZ) \\
\hline \multirow{4}{*}{ Freestall system } & Minimum & 0.825 & 0.911 & 0.818 & 0.760 \\
& Maximum & 0.973 & 1.000 & 0.970 & 1.000 \\
& Mean & 0.901 & 0.968 & 0.901 & 0.910 \\
\multirow{3}{*}{ Tie-stall system } & \pm SD & 0.040 & 0.028 & 0.044 & 0.071 \\
& Minimum & 0.702 & 0.652 & 0.550 & 0.702 \\
& Maximum & 0.961 & 1.000 & 0.904 & 0.961 \\
& Mean & 0.844 & 0.886 & 0.737 & 0.844 \\
& \pm SD & 0.062 & 0.118 & 0.112 & 0.062 \\
& $p$-value & 0.002 & 0.006 & $<0.001$ & 0.005 \\
\hline
\end{tabular}


It is apparent that the highest difference between maximum and minimum values of ITSF indices in all zones can be observed for barns with the tie-stall housing system. At the same time, it can be emphasized that farms with tie-stall systems were characterized by higher differences (7.5-times) between the smallest and largest herd sizes ( 8 vs. 60 cows) compared to the dairy farms with freestall systems, where a 5-fold difference in cow herd size (30 vs. 150 cows) was found. The lowest variation of ITSF values was observed in the social zone in barns with freestall housing systems, however the highest diversification of ITSF values was found in the feeding zone in barns with tie-stall systems. The comparable results of the considered ITSF differences, i.e. 0.240 vs. 0.259 for freestall and tie-stall housing systems respectively were noted for the milking zone.

It can be interesting to indicate that for the social zone, when comparing with other zones, the SD value is lowest $( \pm 0.028)$ for barns with freestall housing systems, while the SD value is highest $( \pm 0.118)$ for barns with tie-stall systems. Generally, the standard deviation shows lower values for freestall systems than for tie-stall housing systems across all zones except for the milking zone.

The results given in Table 3 show significant differences $(p<0.05)$ of ITSF values between the housing systems used in the investigated barns, including all considered areas (zones) where cows have contact with technical infrastructure. The lowest $p$-value $(p<0.001)$ was found for the feeding zone (FZ). This means that the lowest $p$-value for feeding zone was associated with the lowest average ITSF values for the feeding zone (FZ) in both housing systems.

Including the four zones analysed in each barn and a maximum ITSF value of 1.0 for each zone, it is possible to obtain a maximum ITSF value of 4.0 for one barn. The maximum ITSF value is a reference to compare to the sum total of ITSF values calculated in each zone. Such data are given in Figure 2 for the two systems. The proposed cumulative ITSF value is the sum of ITSF values found in the four zones. The cumulative ITSF values were 3.680 and 3.312 for freestall and tie-stall housing systems, respectively. The distance between the cumulative measured and maximum ITSF values was smaller for dairy farms with the freestall system. The cumulative maximum ITSF value can be considered perfect barn conditions, and it seems that attaining this score should be one of the aims for improving farm dairy production.

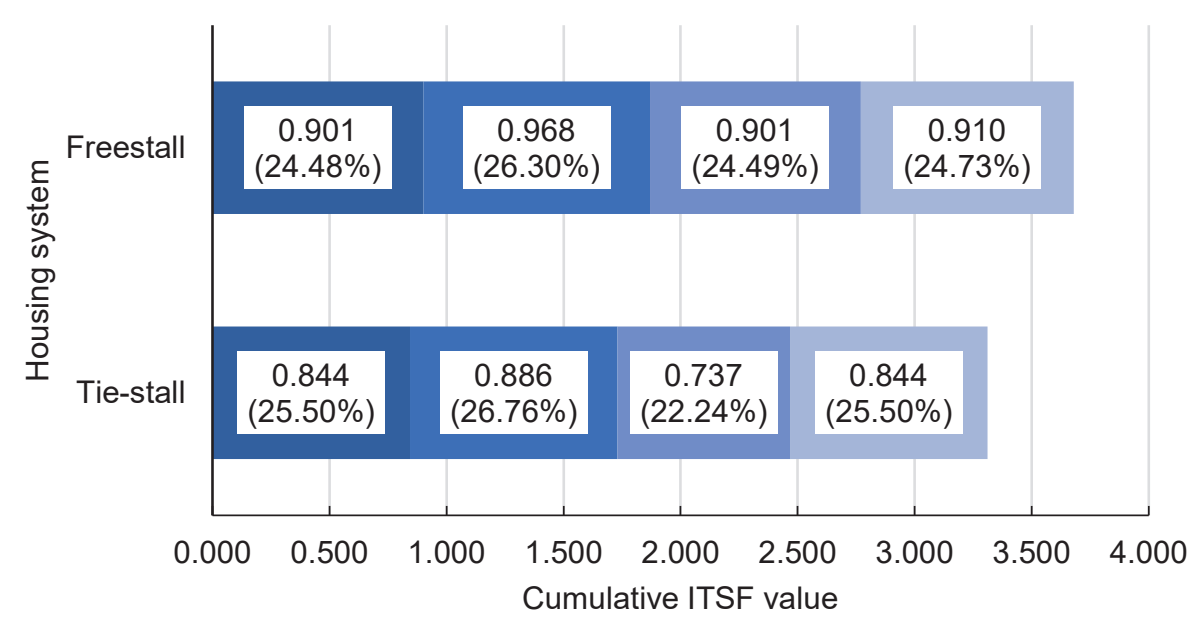

$\square \mathrm{LZ} \backsim \mathrm{SZ} \backsim \mathrm{FZ} \square \mathrm{MZ}$

Fig. 2. ITSF values and percentage share (in brackets) of ITSF values in relation to cumulative ITSF value for the two housing systems including four areas of the barn: LZ =lying zone, $\mathrm{SZ}=$ social zone, $\mathrm{FZ}=$ feeding zone, $\mathrm{MZ}=$ =milking zone

It is valuable to compare the share of each zone's ITSF values in the cumulative ITSF value. The highest percentage share in the cumulative ITSF value is represented by the social zone (SZ) in both the freestall and tie-stall keeping systems (Fig. 2). However, the lowest ITSF percentage share (22.24\%) was found in the feeding zone in farms with tie-stall housing systems.

To consider some differences in the ITSF values, some additional data concerning the investigated barns can be given. The investigated farms with the tie-stall system included 18 barns with the lying area covered by straw and one barn where rubber mats covered the lying area. Of the farms with the freestall system, nine used rubber 
mats, and 10 bedded the stalls with straw. The structure of milking installations in the investigated farms was as follows: bucket milking system - 6 farms, pipeline milking system - 13 farms, milking parlour - 16 farms (11 farms with herringbone and 5 farms with a side-by-side milking system) and AMS - 3 farms (one farm with 1-stall AMS and two farms with 2-stall AMS).

The results show the close relationship between ITSF values and some of the production/technological data collected in the 38 dairy farms (Table 4). The barn usable area and number of lying stalls were correlated with the ITSF values for all of the individually considered zones in barns. In contrast, the annual milk yield per cow, number of rows with lying stalls, and number of drinking bowls were only correlated with the ITSF values for one zone. The other production/technological variables were correlated using the calculated ITSF values in three barn zones.

Table 4. Correlation coefficients of the ITSF values and the variables collected in the 38 investigated dairy farms

\begin{tabular}{|c|c|c|c|c|}
\hline Source of variability & $\mathrm{ITSF}_{\mathrm{Lz}}$ & $\mathrm{ITSF}_{\mathrm{Sz}}$ & $\mathrm{ITSF}_{\mathrm{FZ}}$ & $\mathrm{ITSF}_{\mathrm{Mz}}$ \\
\hline Barn age (years) & $-0.644^{a}$ & -0.280 & $-0.379^{a}$ & $-0.555^{a}$ \\
\hline Barn usable area $\left(\mathrm{m}^{2}\right)$ & $0.465^{a}$ & $0.436^{a}$ & $0.606^{a}$ & $0.537^{\mathrm{a}}$ \\
\hline Milk production (kg/month) & $0.394^{\mathrm{a}}$ & 0.227 & $0.420^{a}$ & $0.512^{\mathrm{a}}$ \\
\hline Annual milk yield per cow (kg/cow/year) & $0.367^{\mathrm{a}}$ & 0.170 & 0.181 & 0.206 \\
\hline Cow herd size (heads) & $0.374^{\mathrm{a}}$ & 0.266 & $0.448^{a}$ & $0.561^{\mathrm{a}}$ \\
\hline Number of lying stalls & $0.503^{a}$ & $0.386^{\mathrm{a}}$ & $0.574^{\mathrm{a}}$ & $0.504^{\mathrm{a}}$ \\
\hline Number of rows with lying stalls & 0.310 & 0.297 & $0.540^{\mathrm{a}}$ & 0.163 \\
\hline Number of milking apparatus & $0.359^{a}$ & $0.329^{a}$ & $0.407^{a}$ & 0.129 \\
\hline Number of drinking bowls & -0.236 & -0.289 & $-0.624^{a}$ & -0.231 \\
\hline $\operatorname{ITSF}_{\mathrm{LZ}}[-]$ & 1.000 & 0.054 & 0.188 & $0.660^{\mathrm{a}}$ \\
\hline $\operatorname{ITSF}_{S Z}[-]$ & 0.054 & 1.000 & $0.358^{a}$ & 0.048 \\
\hline $\operatorname{ITSF}_{\mathrm{FZ}}[-]$ & 0.188 & $0.358^{a}$ & 1.000 & 0.137 \\
\hline ITSF $_{M Z}[-]$ & $0.660^{\mathrm{a}}$ & 0.048 & 0.137 & 1.000 \\
\hline
\end{tabular}

$\mathrm{a}=$ correlation significant; critical values for size $\mathrm{N}=38$ with a significance level $\alpha=0.05$ amount to 0.320 . Description of the ITSF indexes: $\mathrm{ITSF}_{\mathrm{LZ}}=$ for lying zone, $\mathrm{ITSF}_{\mathrm{SZ}}=$ for social zone, $\mathrm{ITSF}_{\mathrm{FZ}}=$ for feeding zone, $\mathrm{ITSF}_{\mathrm{MZ}}=$ for milking zone

\section{Discussion}

In Poland, where the investigations were carried out, approximately $80 \%$ of all dairy cows are kept in barns with tie-stall systems. The results of this study indicate that many dairy cows in Poland are kept under conditions described by lower values of technical standards fulfilment. This suggests that many cows in farms may feel discomfort resulting from contact with the technical infrastructure in barns. The tie-stall housing system is still extensively used for dairy cows in many countries. In Europe, between $20 \%$ and $80 \%$ of cows are tethered at least during the winter (Veissier et al. 2008). In some countries, like Romania, the tie-stall system is used in approximately $75 \%$ of the middle sized and large farms and in $90 \%$ of the small farms (Popescu et al. 2013). Some economic reasons, lack of space, accessible equipment and sometimes convenience motivate many farmers to keep dairy cows tethered. Moreover, the majority of dairy farms with tethered systems are old barn buildings which are not suitable to keep today's large framed dairy cows (FAO 2010). Therefore, it is justified to develop some research approaches to assess the current production conditions in barns with tie-stall and freestall housing systems. Dairy production is the type of activity, where some expectations can be formulated, e.g. in the area of animal welfare, and the efficiency of labour, energy and resource use. When there are some current production conditions and some production expectations, it is possible to measure the difference between the current and expected data. Such general idea was proposed by the method, where the index of technical standards fulfillment (ITSF) plays the key role.

The objective of this study was the proposition of a method to assess how well some production conditions in barns meet national standards and recommendations in order to make practical improvements to farm infrastructure. The index of technical standards fulfillment (ITSF) can be used as an alternative to indices that are currently used to assess some dairy production conditions regarding animal comfort. Additionally, the ITSF can be compared with these other indices to assess some aspects of dairy production including barn conditions. The ITSF can then be used by farmers to assess how current barn conditions meet national standards and recommendations, especially elements used in housing system design. 
To fulfil the practical aim of the proposed method on dairy farms, it may be important to provide farmers access to an electronic version of a simple calculation sheet, where the farmer inputs parameters of interest (e.g. width or length of lying stalls), and according to the general algorithm (Fig. 1) the calculation sheet can generate results, i.e. values of the ITSF in particular zones of the barn.

National standards can include different numbers of technical parameters; however, the general rule of measurements and calculations provides the possibility to expand the proposed ITSF index to other regions/countries. The possibility to include national standards and recommendations make the method more universally applicable. Despite the numerous advantages of the proposed method, there are some disadvantages that must be addressed. One of them can include some details concerning standards on animal housing conditions. For example, Polish standards on lying area for cows and heifers in 2003 included two additional categories, i.e. cows and heifers in pregnancy over 7 month and body mass under $500 \mathrm{~kg}$ (one category) and body mass over $500 \mathrm{~kg}$ (second category). When national standards are as detailed as the above examples, it is difficult to include these details in the calculation of the ITSF index, and difficult for farmers to make practical improvements to farm infrastructure. Therefore, simpler national standards are favoured by the ITSF. For example, in 2010, the two categories above were merged and lying area could easily be used in ITSF calculations. Another important aspect related to the assessment of the farm infrastructure and the dimensions measured is the size of the animals. As sizes of cows vary considerably, mere fulfilment of certain standards and recommendations does not guarantee that the housing conditions obtained will be optimum.

In other methods for assessing dairy housing conditions, such as TGI 35, TGI 200 and ALD, the number of criteria ranges from 30 to 37, whereas the number of housing criteria includes 13 to 36 factors (Hörning 2001). To discuss and compare the numbers of criteria, it is important to question details such as the influencing categories and the approach used to assess dairy housing conditions. Another important element of discussions on the scoring methods used for assessing dairy housing conditions is the percentage of subjective criteria. The method to calculate the ITSF index is based only on measurable and comparable parameters, so subjective aspects other than the accuracy of the measurements are not fully considered.

Another problem concerning methods for assessing dairy housing conditions is repeating the assessed criteria. The problem of repeated data also concerns some aspects of calculating the ITSF index. In barns with tie-stall systems, two zones, the lying and milking areas, were necessarily included as the same functional area (unit). During milking cows are held in the lying area, so in barns with tie-stall systems, the lying and milking areas were measured as one zone. As a result, the ITSF values ( \pm SD) for lying and milking zones are the same (Table 3 ) in the tie-stall system.

Generally, it is interesting that lower mean values of the ITSF indices for tie-stall systems (Table 3) are associated with greater differences between the maximum and minimum values of ITSF indices, whereas higher mean values of the ITSF indices for freestall systems are associated with smaller differences between the maximum and minimum values of the ITSF index. It is therefore possible to conclude that the surveyed freestall housing systems consistently provided better conditions for dairy cattle in barns, whereas conditions in the surveyed tie-stall systems were generally poorer, but also more variable. The highest variation was found in the feeding zone. The feeding area ranks among the most important factors in determining the efficiency of dairy production, so it may be suggested that feeding facilities be improved first in farms with tie-stall housing systems.

Analysis of correlation coefficients (Table 4) show that ITSF indices for all considered zones are positively correlated with barn usable area as well as number of lying stalls. Increasing barn usable area and number of lying stalls can be associated with increasing ITSF index, i.e. lower difference between current housing condition and some standards and recommendations concerning the housing conditions in the barns. Barn usable area and especially number of lying stalls was directly proportional to the number of cows on the farm. Therefore, it is possible to expect that cows kept in bigger herds can meet better conditions concerning barn facilities.

It is valuable to generate propositions for farmers to identify cow welfare/comfort problems. The response to such problems can be an assessment tool to help producers improve cow comfort on their farms (Vasseur et al. 2015), which includes sets of animal-, environment- and management-based measures. The objectives of this study were to develop an on-farm assessment tool that can help farmers assess how well they are meeting their code of practice and that can identify management and environmental modifications that could improve dairy cow comfort on their farms. The codes of practice provide dairy producers with best practice guidance for the care and handling of their cattle. Another source of suggestions for dairy producers are (in most countries) national standards for animal production. Such standards were used to propose the method developed here with a practical approach 
to calculate an index of technical standards fulfilment (ITSF). The ITSF index is the result of measurements that farmers can carry out by using simple hand tools to compare their farms with the available data in national standards and recommendations.

The ITSF index presents one approach to assess conditions created for cows in the most important areas where animals contact technical infrastructure in the barn. The considered index represents the state of the conditions existing in the production areas (lying, social, feeding and milking area) for dairy cows (or other groups of livestock), which can help determine the animal comfort and welfare. Of course, it is possible to include other factors that may influence cow comfort in the assessment tool, such as management practices. However, the idea of the ITSF methodology is to create an index on the basis of measured and standard parameters.

The main rule for the methodological approach concerning ITSF calculation comes down to collating the measured and standard values to find shares of measured data in relation to standard data. The result of the calculation can show the "distance" between perfect conditions (resulting from fulfilment of standards or codes of practice) and the current situation concerning the considered parameter in the investigated barn.

It may be proposed to include the ITSF index as an element of farm control systems to help investigate the longterm consistency of selected animal-related welfare parameters in dairy farms (Winckler et al. 2007).

The proposed method to assess animal housing conditions can become part of recent developments in characterizing animal welfare, i.e., constructing new frameworks to assess animal welfare that are intended to integrate existing knowledge and provide practical tools to improve animal welfare (Sejian et al. 2011).

\section{Conclusions}

Animal life in many areas is necessarily connected to standards, regulations and recommendations. In this way, animal life can be better organized, managed and well-ordered. Studies on animal welfare, comfort and housing conditions are also the premise for more and better-ordered knowledge concerning tools for dairy production assessment. The proposed index of technical standards fulfilment constitutes an alternative tool for assessing housing conditions that translate into cattle welfare. The idea behind this study was to create a simple method to help assess some aspects of dairy housing conditions and to understand how the conditions meet relevant regulations.

The method proposed in this study to calculate ITSF is an example approach to express the results of an investigation using values between 0 and 1 . Such values are characteristic of many indices used in analyses of cattle behaviour and comfort, as presented in the discussion. Delimiting the index between 0 and 1 allows the level of excellence to be presented; i.e., the distance between the calculated value and maximum value ranges from 1 to 0 . As such, it may be easier to compare some indices that also concern animal welfare.

\section{Acknowledgements}

The authors would like to thank the participating farmers for their support during farm visits. We thank Douglas Veira for his constructive comments and Aleksander Lisowski for his help in statistical analysis. This research did not receive any specific grant from funding agencies in the public, commercial, or not-for-profit sectors.

\section{References}

Alban, L., Ersbøll, A.K., Bennedsgaard, T.W. \& Johnsen, P.F. 2001. Validation of welfare assessment methods at herd level: An example. Acta Agriculturæ Scandinavica, Section A Animal Science 51, Supplement 030: 99-102.

Bartussek, H. 1999. A review of the animal needs index (ANI) for the assessment of animals' well-being in the housing systems for Austrian proprietary products and legislation. Livestock Production Science 61: 179-192. https://doi.org/10.1016/S03016226(99)00067-6

Bickert, W.G. 2000. Freestall design. In: Proceedings from the conference Dairy housing and equipment systems: managing and planning for profitability, NRAES-129, Ithaca, NY: National Resource, Agriculture and Engineering Service. p. 205-213.

Blokhuis, H.J., Jones, R.B., Geers, R., Miele, M. \& Veissier, I. 2003. Measuring and monitoring animal welfare: Transparency in the food product quality chain. Animal Welfare 12: 445-455.

Bracke, M.B.M., Metz, J.H.M. \& Spruijt, B.M. 2001. Development of a decision support system to assess farm animal welfare. Acta Agriculturæ Scandinavica, Section A Animal Science 51, Supplement 030: 17-20. 
Capdeville, J. \& Veissier, I. 2001. A method of assessing welfare in loose housed dairy cows at farm level, focusing on animal observations. Acta Agriculturæ Scandinavica, Section A Animal Science 51, Supplement 030: 62-68.

Ceballos, A., Sanderson, D., Rushen, J. \& Weary D.M. 2004. Improving stall design: Use of 3-D kinematics to measure space use by dairy cows when lying down. Journal of Dairy Science 87: 2042-2050. https://doi.org/10.3168/jds.S0022-0302(04)70022-3

de Vries, T.J., von Keyserlingk, M.A.G. \& Weary, D.M. 2004. Effect of feeding space on the inter-cow distance, aggression, and feeding behavior of free-stall housed lactating dairy cows. Journal of Dairy Science 87: 1432-1438. https://doi.org/10.3168/jds. S0022-0302(04)73293-2

Drissler, M., Gaworski, M., Tucker, C.B. \& Weary, D.M. 2005. Freestall maintenance: Effects on lying behavior of dairy cattle. Journal of Dairy Science 88: 2381-2387. https://doi.org/10.3168/jds.S0022-0302(05)72916-7

FAO 2010. Tie stall housing systems on dairy farms. http://www.fao.org/fileadmin/user_upload/animalwelfare/TieStalls.pdf

Fregonesi, J.A., von Keyserlingk, M.A.G., Tucker, C.B., Veira, D.M. \& Weary, D.M. 2009. Neck-rail position in the free stall affects standing behavior and udder and stall cleanliness. Journal of Dairy Science 92: 1979-1985. https://doi.org/10.3168/jds.2008-1604

Haley, D.B., de Passillè, A.M. \& Rushen, J. 2001. Assessing cow comfort: effects of two floor types and two tie stall designs on the behaviour of lactating dairy cows. Applied Animal Behaviour Science 71: 105-117. https://doi.org/10.1016/S0168-1591(00)00175-1

Hörning, B. 1997. Tiergerechtheit und Verfahrenstechnik eingestreuter Milchviehlaufställe in der Praxis. University of Kassel, Faculty of Agriculture, Witzenhausen, Germany. Ph.D. Thesis. 212 p. (in German).

Hörning, B. 2001. The assessment of housing conditions of dairy cows in littered loose housing systems, using three scoring methods. Acta Agriculturæ Scandinavica, Section A Animal Science 51, Supplement 030: 42-47.

Knierim, U. \& Winckler, C. 2009. On-farm welfare assessment in cattle: validity, reliability and feasibility issues and future perspectives with special regard to the Welfare Quality ${ }^{\circledR}$ approach. Animal Welfare 18: 451-458.

McFarland, D.F. 2000. Feed area and water space design. In: Proceedings from the conference Dairy housing and equipment systems: managing and planning for profitability, NRAES-129, Ithaca, NY: National Resource, Agriculture and Engineering Service. p. 297-314.

McFarland, D.F. \& Gamroth, M.J. 1994. Freestall designs with cow comfort in mind. In: Bucklin, R. (ed.). Dairy Systems for the 21st Century. Proceedings of the III International Dairy Housing Conference, American Society for Agricultural Engineers: St. Joseph, MI. p. 145-158.

Popescu, S., Borda, C., Diugan, E.A., Spinu, M., Groza, I.S. \& Sandru, C.D. 2013. Dairy cows welfare quality in tie-stall housing system with or without access to exercise. Acta Veterinaria Scandinavica 55:43. https://doi.org/10.1186/1751-0147-55-43

Sejian, V., Lakritz, J., Ezeji, T. \& Lal, R. 2011. Assessment methods and indicators of animal welfare. Asian Journal of Animal and Veterinary Advances 6: 301-315. https://doi.org/10.3923/ajava.2011.301.315

Sundrum, A., Andersson, R. \& Postler, G. 1994. Ein Leitfaden zur Beurteilung von Haltungssystemen für Rinder, Kälber, Legehenen und Schweine. Bonn, Germany: Verlag Köllen. Tiergerechtheitsindex-200. 211 p. (in German).

Tucker, C.B., Weary, D.M. \& Fraser, D. 2004. Freestall dimensions: effects on preferences and stall usage. Journal of Dairy Science 87: 1208-1216. https://doi.org/10.3168/jds.S0022-0302(04)73271-3

Tucker, C.B., Weary, D.M. \& Fraser, D. 2005. Influence of neck-rail placement on free-stall preference, use, and cleanliness. Journal of Dairy Science 88: 2730-2737. https://doi.org/10.3168/jds.S0022-0302(05)72952-0

Tucker, C.B., Zdanowicz, M. \& Weary, D.M. 2006. Brisket boards reduce freestall use. Journal of Dairy Science 89: 2603-2607. https://doi.org/10.3168/jds.S0022-0302(06)72337-2

Vasseur, E., Gibbons, J., Rushen, J., Pellerin, D., Pajor, E., Lefebvre, D. \& de Passillè, A.M. 2015. An assessment tool to help producers improve cow comfort on their farms. Journal of Dairy Science 98: 698-708. https://doi.org/10.3168/jds.2014-8224

Veissier, I., Andanson, S., Dubroeucq, H. \& Pomiès, D. 2008. The motivation of cows to walk as thwarted by tethering. Journal of Animal Science 86: 2723-2729. https://doi.org/10.2527/jas.2008-1020

von Keyserlingk, M.A.G., Rushen, J., de Passillè, A.M.B. \& Weary, D.M. 2009. The welfare of dairy cattle - Key concepts and the role of science. Journal of Dairy Science 92: 4101-4111. https://doi.org/10.3168/jds.2009-2326

Winckler, C., Brinkman, J. \& Glatz, J. 2007. Long-term consistency of selected animal-related welfare parameters in dairy farms. Animal Welfare 16: 197-199. 